\title{
Economic Effects of Product Packaging on Consumer Shopping Behavior: The Case of Lebanon
}

\author{
Bassam Charif Hamdar ${ }^{1, ~ *, ~ M o n a ~ A l ~ D a n a ², ~ G h i d a ~ A l ~ C h a w a ~}{ }^{2}$ \\ ${ }^{1}$ Department of Economics, American University of Science and Technology, Beirut, Lebanon \\ ${ }^{2}$ Department of Business Administration, MBA Program, American University of Science and Technology, Beirut, Lebanon
}

Email address:

bhamdar@aust.edu.lb (B. C. Hamdar)

${ }^{*}$ Corresponding author

\section{To cite this article:}

Bassam Charif Hamdar, Mona Al Dana, Ghida Al Chawa. Economic Effects of Product Packaging on Consumer Shopping Behavior: The Case of Lebanon. American Journal of Theoretical and Applied Business. Vol. 4, No. 2, 2018, pp. 44-47. doi: 10.11648/j.ajtab.20180402.12

Received: April 10, 2018; Accepted: April 26, 2018; Published: May 19, 2018

\begin{abstract}
In today's competitive market place, it's harder than ever to attract a consumer's attention. It's estimated that the average consumer spends less than a second scanning shelves, and in that time, will make a decision on whether or not to purchase any given product. The discipline of package design focuses on producing a container that will get noticed. By skillfully teaming colorful graphics, a unique shape, or any other eye-arresting method, the package designer is a key player in any company's marketing effort. No matter how beneficial the product inside the container may be, unless a consumer decides to pick it up, that product will never get tested. Moreover, many studies indicate that consumers have high motivation to pay for Packaging related to energy efficient products. Subsequently; the pristine packaging color-coded, which designed by professionals to be the silent salesman of the brand, undoubtedly, has considerable impact on the purchasing decision. The objective of this study is to determine the impact of packaging on customer's buying behavior. Data have been collected through a questionnaire and analyzed using the SPSS software. Furthermore, a sample of 200 respondents has been utilized to indicate that design packaging has a critical role to play in the consumption of products in Lebanon. Additionally, the results of the study reflected that packaging, especially, Color and Wrapping Design play a vital role in the decision buying process of the consumer.
\end{abstract}

Keywords: Economic Effect, Packaging, Buying Behavior, Purchasing Decision, Independent and Dependent Variables, Lebanon

\section{Introduction}

People are visual creatures by nature. What differentiates a bad company from a good company is the fact that, the latter knows how to attract customers' attention with the help of packaging design. While an interesting and eye-catching logo does play a big part in marketing a product, nothing comes as close as the effects a visually appealing and striking design has on prospective customers. A good design should always reflect the product and the creativity and personality of the company. There is more, however, to packaging design than simply ensuring a package looks appealing [1].

Underwood pointed out [2] that Packaging became itself an advertisement tool for its company. The consumers are enthused by the packaging quality, color, wrapper, and other characteristics of packaging. Packaging became an important selling proposition, which stimulates buying behavior. It increases sales and reduces marketing and promotional costs, a good reason for designing companies to utilize. According to Underwood et al. [3], Packaging works as an instrument for creating an image in customer's mind, and increases expectations for what is inside the displayed product. Especially, perfume commercials, where perfume cannot be smelled but, nevertheless, consumers buy it due to the expectations created by the bottle's shape. This indicates that people see the product image with positive attitude based on its packaging.

\section{Objectives of the Study}

The following main objectives are to be addressed in this 
paper:

1. To find out the effects of packaging on consumers purchasing behavior.

2. To measure the impact of packaging on the consumer.

3. To identify attractive elements for designing product packaging.

\section{Literature Review}

L Renaud [4] worked on the Influence of Eco-Labeling on Consumer Behavior. The main aim of the study was to measure the importance of labeling on Packaging compared to other product features (like brand, price, etc.) for shoppers' buying decisions. The method selected was based on choice analysis. The study attempted to analyze whether the importance of the labeling and packaging varies among product groups. A total of 302 customers were surveyed; the variables chosen within this study were, present mood, time, buying purpose, and marketing technique. The most important result of the analysis was the high motivation to pay for Packaging related to energy efficient products.

Limon et al. [5] worked on the packaging design as a resource for the construction of brand Identity. The result was that there were no meaningful guidelines for developing packaging design, shapes, finishes, sizes, images, colors, impressions, purchase intention, and brand. Furthermore, According to Karbasivar and Yarahmadi [6], cash discount and window display have important role in encouraging impulse buying.

Garber et al. [7] indicated that Packages are claimed to attract attention when their appearances are not typical within a product class; While, Schoormans and Robben [8] asserted that unusual packages attract attention no matter what. However, Maiksteniene and Auruskeviciene [9] show that colors and shapes attract more attention. Moreover, Underwood [2] points out that packaging allows positioning to be transferred live.

As it accompanies products, packaging lives in consumers' homes and potentially becomes an intimate part of their lives, creating a type of live experience between the purchaser and the brand [10].

Packaging is a very important element of the marketing mix. The pristine packaging color-coded, which designed by professionals to be the silent salesman of the brand, undoubtedly, has considerable impact on the purchasing decision [11]. However, Sun et al. stated that a variety of factors affect consumers' choices of cosmetics. These factors may include sensory appeal, convenience of usage, health, season, color, age of the consumers, etc. Sensory appeal could be a major factor that contributes to consumers' choice of cosmetics. "Brightening" and "illuminating" were among the most popular terms used as product claims in 2013 in UK [12]. Finally, one crucial element of successful packaging is an icon: "Emotions are often connected to brand icons as memories and feelings can be brought up on sight, leading to long-term relationships between the brand and the consumer [13].

\section{Research Methodology}

The hypothetical framework between independent and dependent variables can be stated as follows:

Dependent Variable:

1. Consumer's Buying Behavior

Independent variables:

1. Color (Draws attention \& affects mood).

2. Packaging material (consumers seek high quality packaging).

3. Wrapper (mostly children below 18 are attracted highly by the wrapper used).

\subsection{Research Approach}

A questionnaire on the basis of the objectives of the study including a sequence of well-arranged questions was distributed to university and school students. The data were later collected and transformed into descriptive analysis, in a quantitative approach.

The Survey is designed with the following objectives:

1. To measure the role of packaging in consumer buying behavior.

2. To estimate the percentage of students who consider the packaging design an essential element of their purchasing decision.

3. To determine the perceptions of students concerning the impact of the packaging design on their decision to make a purchase.

The survey method utilized was based on a longitudinal study; which enables researchers to study different samples from different universities and schools at different time horizons, by taking into consideration time changes that will allow one to better understand the students' opinions vis-àvis the effect of packaging design on the buying behavior.

\subsection{Population and Sample Size}

For this study the target population consists of students from different universities and different schools in Lebanon. The total sample size is 200 and this paper utilized a simple random sampling technique in order to generalize the finding, because it's the most applicable for non-biased answers, in addition to have different opinion from different genders, positions, age, educational background etc.

\subsection{Data Collection}

This paper utilized an exploratory research method, and the questionnaire was analyzed descriptively.

Data Sources:

1. Primary Data was collected from the respondents by administering a structured questionnaire distributed at schools and universities.

2. Secondary Data was collected from published files and reports.

\subsection{Sample Design}

A quantitative method is used in this paper. It aims at 
measuring the effect of packaging design on buying behavior. Random Sampling has been used to collect data from the respondents. Primary data was collected for this paper via a systematic and structured questionnaire, which was divided into three sections:

1. Section A: designed to assess the respondents' attitudes and opinions regarding their satisfaction level. This series of questions was rated on a Likert scale of five anchors i.e.; (1) strongly Agree, (2) Agree, (3) Neutral, (4) Disagree, and (5) strongly Disagree.

2. Section B: designed to assess the respondents' demographics in order to understand their background to analyze the motives behind their answers.

\subsection{Data Processing and Analysis}

The questionnaires are coded using a specific code for each variable, and the variables are going to be entered into SPSS software [14] that will help provide several procedures for data analysis. Moreover, the SPSS software is used to describe, summarize, and measure central tendency (average) and dispersion. And finally, The Pearson's correlation is used to find correlation between the variables.

\section{Results}

It is believed that $60-70 \%$ of all buying choices are made in the store. The packaging is the last point of communication between a product and a consumer. Hence, packaging is one of the most vital points of interaction with the consumer. Normally, consumers relate packaging with the quality of the product and such a correlation impacts the purchasing behavior. Therefore, companies should invest in the packaging to deliver the epic brand image in the buyer's mind. Researchers evidenced such artistic features like color, brightness and design impacts, when the customer's eyes land on the shelves as follows:

Table 1. Buying Behavior.

\begin{tabular}{|c|c|c|c|c|c|}
\hline & $\mathbf{N}$ & Minimum & Maximum & Mean & Std. Deviation \\
\hline Buying Behavior Valid N (list-wise) & 200 & 1 & 5 & 3.63 & 0.912 \\
\hline
\end{tabular}

In table 1, the minimum, maximum, mean and the values of standard deviation of the Buying Behavior Variable have been shown. The number of observations of each variable is 200 . The Minimum value is 1 , while the Maximum value is 5 . The Mean value is 3.63 and the standard deviation is 0.912 .

Table 2. Packing Color.

\begin{tabular}{llllll}
\hline & N & Minimum & Maximum & Mean & $\begin{array}{l}\text { Std. } \\
\text { Deviation }\end{array}$ \\
\hline $\begin{array}{l}\text { Packing } \\
\text { Color }\end{array}$ & 200 & 1 & 5 & 3.52 & 0.934 \\
\hline
\end{tabular}

In table 2 , the minimum value is 1 , the maximum value is 5 , and the mean value is 3.52 , while the value of standard deviation is 0.934 . Moreover, the Mean shows the central tendency of the values of a variable.

Table 3. Packing Quality.

\begin{tabular}{llllll}
\hline & N & Minimum & Maximum & Mean & $\begin{array}{l}\text { Std. } \\
\text { Deviation }\end{array}$ \\
\hline $\begin{array}{l}\text { Packing } \\
\text { Quality }\end{array}$ & 200 & 1 & 5 & 3.62 & 0.911 \\
\hline
\end{tabular}

In table 3 , the minimum value is 1 , the maximum values is 5 , and the mean value is 3.62 , while the value of standard deviation is 0.911 . The Mean varies between $+/-0.911$.

Table 4. Wrapper design.

\begin{tabular}{llllll}
\hline & N & Minimum & Maximum & Mean & $\begin{array}{l}\text { Std. } \\
\text { Deviation }\end{array}$ \\
\hline $\begin{array}{l}\text { Wrapper } \\
\text { design }\end{array}$ & 200 & 1 & 5 & 3.51 & 0.813 \\
\hline
\end{tabular}

Table 4 , shows that the minimum value is 1 , the maximum value is 5 , and mean value is 3.51 , while the value of standard deviation is 0.813 . The Mean varies between $+/-0.813$.

\subsection{Economic Point of View}

The shopper's economic decisions are mainly influenced by their needs, personality, culture, and by the sight attraction of the product. The consumers consider the price as an opportunity cost for the product. So, the decision depends on the total utility from buying the good, and the more the customer likes the packaging the more he/she believes it is an addition to the utility level and the image dimension. The economic view of a consumer depends on his/her personality in seeking for value of the product. Buyers satisfy their needs by comparing price, quality, and packaging of the product with the available alternatives. Nowadays, packaging plays an important role in either purchasing or choosing another product.

\subsection{Demand and Supply}

According to Frydman [15], "the big idea here is that perceptual processes happen in the brain in parallel with economic value computations, and thus influence how economic decisions are made."

Packaging spending is one of those vague areas of supply and demand theory, where one doesn't really know exactly what might happen. Therefore, it is guessed that packaging affects customer's preferences in a positive way, and that the outcome would be an increase in demand (the demand curve will shift rightward) Ellwood [16]. However, creating good and eye-catching package costs companies a lot of cash.

\section{Conclusion and Recommendation}

\subsection{Conclusion}

Packaging plays a huge role in advertising and promotion campaigns. It shows to have a significant impact on 
consumer buying behavior. Colors, shape, and quality catch consumer's attention and interest. The shopper's purchase decision depends on his/her interests, time, and product characteristics. Elements of packaging are highly important for consumer's purchase decision. Most consumers care about the packaging size, color and how easy to open and handle. Moreover, packaging is working better than advertising, and could set a brand apart from its opponents. Most consumers like the item's quality after they purchase the desired packaged product.

\subsection{Recommendation}

The authors greatly recommend that the companies which seek high purchasing volume to implement a future plan based on packaging design. Design packaging, nowadays, works better than advertising and has the power to influence customer choices. Furthermore, packaging with its carefully thought-out aesthetic features, can affect consumers' emotions, and can bring their memories to life with its colors, design, shape, and can impact consumer's culture with its form. It is this creation of a product's personality and human emotion that matters the most.

\section{References}

[1] Importance of Packaging Design-Your Branding Doesn't Stop With Your Logo (2013, July 15). Retrieved from https://36creative.com/.../importance-of-packaging-designyour-branding-doesnt-stop.

[2] Underwood, R. L., (2003). The Communicative Power of Product Packaging: Creating Brand Identity Via Lived and Mediated Experience. Journal of Marketing Theory and Practice, winter, 62-76.

[3] Underwood, R. L, Noreen M. Klein, Raymond R. Burke, (2001). "Packaging Communication: Attentional Effects of Product Imagery", Journal of Product \& Brand Management, Vol. 10 Issue: 7, pp. 403-422, https://doi.org/10.1108/10610420110410531

[4] L Renaud (2007). The Influence of Label on Wine Consumption: Its Effects on Young Consumerse Perception of Authenticity and Purchasing Behavior, Bologna, Italy.

[5] Limon, Y., Lynn R. Kahle, and Ulrich R. Orth (2009). Package
Design as a Communications Vehicle in Cross-Cultural Values Shopping. Journal of International Marketing: March 2009, Vol. 17, No. 1, pp. 30-57.

[6] Karbasivar, Alireza and Hasti Yarahamadi (2011). Evaluating Effective Factors on Consumer Impact Buying Behavior, Asian Journal of Business management, 2(4):174-181.

[7] Garber, L. L., Burke, R. R., \& Jones, J. M. (2000). The Role of Package Color in Consumer Purchase Consideration and Choice. Report-Marketing Science Institute Cambridge Massachusetts.

[8] Schoormans, J. P., \& Robben, H. S. (1997). The Effect of New Package Design on Product Attention, Categorization and Evaluation. Journal of Economic Psychology, 18(2), 271287. http://dx.doi/10.1016/s0167-4870(97)00008-1

[9] Maiksteniene, K., and Auruskeviciene, V. (2008). 'Manufacturer and Retailer Brand Acceptance Under Different Levels of Purchase Involvement', Inzinerine EkonomikaEngineering Economics (1), pp. 90-96.

[10] Lindsay, D. (1997). "Shaped to Sell: Package Innovation Can Boost Revenue, Decrease Cost and Build Brand", Beverage World, Vol. 116, pp. 91-2.

[11] Parker, C., Roper, S., and Medway, D., (2015). Back to Basics in the Marketing of Place: The Impact of Litter Upon Place Attitudes, Journal of Marketing Management, 31:9-10, 10901112, DOI: $10.1080 / 0267257 X .2015 .1035307$

[12] Sun, C., Adhikari, K., \& Koppel, K. (2015). An Exploratory Study of the Factors That May Affect Female Consumers' Buying Decision of Nail Polishes. Cosmetics, 2(2), 187-195.

[13] Jarski, veronica. (2014, September 16). How Product Packaging Affects Buying Behavior. Retrieved from www.marketingprofs.com/.../how-product-packaging-affectsbuying-decisions-infogr

[14] IBM Corp. Released (2013). IBM SPSS Statistics for Windows, Version 22.0. Armonk, NY: IBM Corp

[15] Frydman, Cary and Mormann, Milica Milosavljevic (2018). The Role of Salience and Attention in Choice Under Risk: An Experimental Investigation (January 4, 2018). Available at SSRN: $\quad$ https://ssrn.com/abstract $=2778822$ or http://dx.doi.org/10.2139/ssrn.2778822

[16] Ellwood, I. (2000). The Essential Brand Book: Over 100 Techniques to Increase Brand Value, London, Kogan Page Limited. 